\title{
Neuroendocrine Responses and Body Composition Changes Following Resistance Training Under Normobaric Hypoxia
}

\author{
by \\ Jakub Chycki ${ }^{1}$,Miłosz Czuba ${ }^{1}$, Artur Gołaśs Adam Zając ${ }^{1}$, Olga Fidos-Czuba ${ }^{1}$, \\ Adrian Młynarz', Wojciech Smótka²
}

The aim of the present study was to evaluate the effects of a 6 week resistance training protocol under hypoxic conditions ( FiO2 $=12.9 \%, 4000 \mathrm{~m}$ ) on muscle hypertrophy. The project included 12 resistance trained male subjects, randomly divided into two experimental groups. Group 1 ( $n=6$; age $21 \pm 2.4$ years; body height $[B H] 178.8 \pm 7.3 \mathrm{~cm}$; body mass $[B M] 80.6 \pm 12.3 \mathrm{~kg})$ and group $2(n=6 ;$ age $22 \pm 1.5$ years; $B H 177.8 \pm 3.7 \mathrm{~cm} ; B M 81.1 \pm 7.5 \mathrm{~kg})$. Each group performed resistance exercises alternately under normoxic and hypoxic conditions $(4000 \mathrm{~m})$ for 6 weeks. All subjects followed a training protocol that comprised two training sessions per week at an exercise intensity of $70 \%$ of 1RM; each training session consisted of eight sets of 10 repetitions of the bench press and barbell squat, with 3 min rest periods. The results indicated that strength training in normobaric hypoxia caused a significant increase in BM $(p<$ $0.01)$ and fat free mass (FFM) $(p<0.05)$ in both groups. Additionally, a significant increase $(p<0.05)$ was observed in IGF-1 concentrations at rest after 6 weeks of hypoxic resistance training in both groups. The results of this study allow to conclude that resistance training (6 weeks) under normobaric hypoxic conditions induces greater muscle hypertrophy compared to training in normoxic conditions.

Key words: hypoxia, muscle hypertrophy, resistance training, endocrine response.

\section{Introduction}

Over the past few decades, hypoxic training has gained popularity in competitive sport as an effective method for improving performance, especially endurance (Czuba et al., 2011, 2013, 2014). Hypoxia is a condition in which some organs or the whole organism is deprived of adequate oxygen supply. Evidence indicates that hypoxia deteriorates exercise performance (Amann et al., 2006; Perrey, 2009), which is accompanied by a lowered $\mathrm{O} 2$ partial pressure in arterial blood (Pao2). This status reduces O2 delivery to tissues and negatively affects muscle metabolism and contractibility (Hogan, 1999). Chronic oxygen deprivation initiates many physiological changes, the most prominent ones

being loss of body mass and protein stores (Macdonald, 2009). Chronic hypoxia has also been reported to be an important factor in skeletal muscle atrophy at moderate altitudes (Bharadwaj et al., 2000). On the other hand, Etheridge et al. (2011) indicated that breathing normobaric hypoxic air $(\mathrm{FiO} 2=12 \%)$ in a post-absorptive state did not modify muscle protein synthesis at rest, but blunted the increase in protein synthesis induced by exercise. Acute hypoxia was also shown to inhibit muscle protein synthesis (Koumenis et al., 2006) primarily by inhibiting the mechanistic target of rapamycin complex 1 (mTORC1) via activation of the AMP-activated protein kinase (AMPK) (Liu, 2006) and increased

1 - The Jerzy Kukuczka Academy of Physical Education in Katowice, Department of Sports Training, Poland.

2- Medical University of Silesia School of Medicine in Katowice,Poland. 
expression of protein regulated in development and DNA damage response 1 (REDD1) (Brugarolas et al., 2004).

Hypoxia has also been linked to stimulation of muscle hypertrophy. It was postulated that by placing the entire body in a hypoxic environment, such as a hypoxic chamber, muscle hypertrophy could be more efficient. Nishimura et al. (2010) reported that highintensity $(70 \%$ of $1-\mathrm{RM})$ training induced greater muscle hypertrophy in subjects who trained for 6 weeks in a hypoxic chamber $(\mathrm{FiO} 2=16 \%, \sim 2000$ $\mathrm{m})$ than in those exercising in normoxia without differences in the rate of perceived exertion. Muscle strength was significantly increased after 6 weeks of training in both normoxic and hypoxic groups; however, training for a shorter time period (namely 3 weeks) induced these changes only in the hypoxic group, suggesting that exposure to hypoxia accelerated the increase in muscle strength (Nishimura et al., 2010). According to a recent report, occlusion training (i.e., local hypoxia) alone can limit muscle atrophy in case of muscle disuse and induce hypertrophy when coupled with resistance training (Loenneke et al., 2012). However, there appears to be a threshold corresponding to $\sim 4500 \mathrm{~m}$ of altitude above which hypoxia does not induce any beneficial effects on muscle hypertrophy when combined with resistance training (Friedman et al., 2003).

Based on the above observations, we attempted to test in a crossover study a hypothesis that a 6 week resistance training program under hypoxic conditions $(\mathrm{FiO} 2=12.9 \%$, $4000 \mathrm{~m}$ ), including two weekly high intensity training sessions, would cause a greater increase in muscle hypertrophy compared to normoxic conditions.

\section{Material and Methods}

\section{Participants}

The study included twelve healthy, recreationally resistance trained male subjects, with at least 3 years of training experience. The subjects were randomly divided into two experimental groups; namely, group $1(\mathrm{n}=6$; age $21 \pm 2.4$ years; body height $[\mathrm{BH}] 178.8 \pm 7.3 \mathrm{~cm}$; body mass [BM] $80.6 \pm 12.3 \mathrm{~kg}$; fat content [\%BF] $23.3 \pm 4.6)$, and group $2(\mathrm{n}=6$; age $22 \pm 1.5$ years; BH $177.8 \pm 3.7 \mathrm{~cm}$; BM $81.1 \pm 7.5$ kg; \%BF $18.3 \pm$
3.0). The research project was approved by the Ethics Committee for Scientific Research at the Academy of Physical Education in Katowice, Poland.

\section{Experimental design}

The research project had three series (S1, S2, S3) of testing in the laboratory. The 2nd and 3rd series were preceded by 6 weeks of strength training. The first series of testing (S1) was conducted at the beginning of the training protocol to determine the initial values of analyzed variables. Two days before S1, all participants were familiarized with the testing procedures. After S1, a 6 week resistance training protocol was applied under different environmental conditions. Group 1 trained under normobaric hypoxia, equivalent of the altitude of $4000 \mathrm{~m}$ and group 2 trained under normoxic conditions. The second series of testing (S2) was performed three days after the cessation of the resistance training program. The 6 week training protocol was repeated; however, the environmental conditions were reversed for both groups; i.e., group 1 trained under normoxic, while group 2 under hypoxic conditions (the equivalent of $4000 \mathrm{~m}$ altitude), with training loads adjusted to each individual. Three days after the second 6 week resistance training period, the last series of testing (S3) was performed.

\section{Testing protocol}

The testing procedures for the S1, S2 and S3 series were the same. Before breakfast and after an overnight fast, blood samples and body measurements were taken. The antecubital venous blood samples were collected to determine resting levels of testosterone (T), cortisol (C), growth hormone (GH) and insulinlike growth factor 1 (IGF-1). Blood plasma and serum were separated using routine procedures and processed immediately or kept frozen at $-70 \mathrm{o}$ $\mathrm{C}$ until analysis. To determine the serum levels of $\mathrm{T}$ and $\mathrm{C}$, the radioimmunological methods were employed using the RIA Testosterone and Cortisol RIA kits (Beckman Coulter). Serum GH and IGF-1 levels were assayed by the radioimmune method with the DSL-1900 IRMA diagnostic kit (Diagnostic System Laboratories, Webster, TX, USA). Serum IGF-1 concentrations were determined utilizing an immunoradiometric assay (IRMA) kit (DSL-2800 Active IGF-1, Diagnostic System Laboratories, Webster, TX, 
USA).

Body height was measured to the nearest $0.1 \mathrm{~cm}$ with digital stationmaster BSM170 (InBody) and body mass was determined to the nearest $0.1 \mathrm{~kg}$ with a medical scale (InBody 570). Body composition was evaluated by dual-energy x-ray absporptiometry (DEXA) (Discovery Wi, HOLOGIC). Two hours after a light mixed meal (400 kcal) (carbohydrates, 50\%; proteins, 20\%; fats, $30 \%)$, a one repetition maximum (1RM) test protocol in accordance with Kraemer (2014) was administered to determine the level of maximum strength from which appropriate training loads were calculated.

\section{Training program}

The resistance exercise protocol applied during the study was the same for both groups, but performed under different environmental conditions during the selected training periods (6 weeks). For 6 weeks, all subjects performed two high intensity resistance training sessions per week, with a 3 day recovery period between sessions. During the first training period (6 weeks), group 1 trained in a normobaric hypoxic chamber at a simulated altitude of $4000 \mathrm{~m}$ (FiO2 $=$ $12.9 \%$ ). Group 2 performed training sessions in the same chamber, but under normoxic conditions. After 6 weeks of strength training, environmental conditions were reversed for both groups (group 1, normoxia, and group 2, normobaric hypoxia) with adjusted training loads.

Each training session for both groups proceeded at an exercise intensity of $70 \%$ of $1 \mathrm{RM}$, and was comprised of 8 sets of 10 repetitions of the bench press and barbell squat. The rest periods between sets included 3 min passive recovery. Before each exercise, subjects in both groups performed a $10 \mathrm{~min}$ general warm-up. Training loads during the training sessions in both groups were increased individually by $5 \mathrm{~kg}$ when a subject completed all repetitions (160) during a session. Besides registering the intensity and volume of the training process, pre- and postexercise capillary blood samples were drawn to determine LA concentration, acid-base balance and saturation of hemoglobin after each 2 weeks of training.

\section{Statistical analysis}

The obtained data were analyzed statistically using Statistica 10.0 software (StatSoft). Basic descriptive statistics were calculated and all variables were examined for normal distribution. To determine the influence of normobaric hypoxia on body composition, ANOVA (group \& training) with repeated measures was applied. When significant differences in the F ratio were found, Tukey's post hoc tests were applied. The level of statistical significance was set at $\mathrm{p}<0.05$.

\section{Results}

The average values of body mass and body composition are presented in Tables 1 and 2 . The results of ANOVA with repeated measures showed a statistically significant effect of the two main factors (group \& training) on considered variables, namely: body mass $(\mathrm{BM}, \mathrm{F}=11.321, \mathrm{p}=$ 0.001), fat free mass (FFM; $F=9.436, p=0.002)$, FFM plus bone mineral content (FFM+BMC; $\mathrm{F}=$ $8.964, p=0.003$ ), $\%$ body fat content (\%fat; $F=$ $4.714, \mathrm{p}=0.041)$, and IGF-1 concentration at rest (IGF-1; $F=7.326, p=0.01$. The training program used in this research did not significantly affect fat mass (FM) as well as testosterone (T), growth hormone (GH) and cortisol (C) levels.

Post-hoc analysis indicated that strength training in normobaric hypoxia caused a significant $(p<0.01)$ increase in BM and an increase $(p<0.05)$ in FFM and FFM+BMC in both groups (Tables 1 and 2). Additionally, body fat content in group 2 was significantly reduced $(\mathrm{p}<$ $0.05)$ after training in hypoxia. Resistance training under normoxic conditions did not affect body composition in group 2, however, a tendency ( $\mathrm{p}<$ 0.09) for decreased BM, FFM and FFM+BMC in group 1 was observed (second 6 weeks of resistance training under hypoxic conditions) (Tables 1 and 2).

Tables 3 and 4 indicate the impact of resistance training under hypoxic and normoxic conditions on neuroendocrine responses. A significant increase $(p<0.05)$ was observed in IGF-1 concentrations at rest after 6 weeks of hypoxic resistance trainings in both groups (Tables 3 and 4, respectively). However, no significant changes were detected in T, GH and C levels, indicated that the responses in IGF-1 levels were specific. 


\begin{tabular}{|c|c|c|c|c|}
\hline \multicolumn{5}{|c|}{$\begin{array}{l}\text { Table } 1 \\
\text { Average values of body mass and selected variables of body composition } \\
\text { at rest before and after the first } 6 \text { weeks of resistance training. } \\
\text { All data are presented as mean } \pm S D, \# p<0.01,{ }^{*} p<0.05\end{array}$} \\
\hline \multirow[t]{2}{*}{ Variable } & \multicolumn{2}{|c|}{ Group 1 - Hypoxia } & \multicolumn{2}{|c|}{ Group 2- Normoxia } \\
\hline & Before training & After training & Before training & After training \\
\hline $\mathrm{BM}(\mathrm{kg})$ & $80.6 \pm 12.3$ & $83.0 \pm 12.4 \#$ & $81.1 \pm 7.5$ & $81.2 \pm 8.4$ \\
\hline FFM (kg) & $58.6 \pm 5.3$ & $60.6 \pm 5.2^{*}$ & $63.1 \pm 3.8$ & $63.2 \pm 3.6$ \\
\hline FFM+BMC (kg) & $61.8 \pm 5.4$ & $63.7 \pm 5.3^{*}$ & $66.2 \pm 3.6$ & $66.4 \pm 3.4$ \\
\hline $\mathrm{FM}(\mathrm{kg})$ & $18.8 \pm 7.0$ & $19.2 \pm 7.0$ & $14.9 \pm 4.1$ & $14.7 \pm 4.9$ \\
\hline$\%$ FAT & $23.3 \pm 4.6$ & $23.1 \pm 4.4$ & $18.3 \pm 3.0$ & $18.1 \pm 3.6$ \\
\hline
\end{tabular}

\begin{tabular}{|c|c|c|c|c|}
\hline \multicolumn{5}{|c|}{$\begin{array}{l}\text { Average values of body mass and selected variables of body composition before } \\
\text { and after the second period of } 6 \text { week resistance training. All data are mean } \pm S D,{ }^{*} p<0.05\end{array}$} \\
\hline \multirow[t]{2}{*}{ Variable } & \multicolumn{2}{|c|}{ Group 1 - Normoxia } & \multicolumn{2}{|c|}{ Group 2- Hypoxia } \\
\hline & $\begin{array}{l}\text { Before } \\
\text { training }\end{array}$ & $\begin{array}{c}\text { After } \\
\text { training }\end{array}$ & $\begin{array}{l}\text { Before } \\
\text { training }\end{array}$ & $\begin{array}{l}\text { After } \\
\text { training }\end{array}$ \\
\hline $\mathrm{BM}(\mathrm{kg})$ & $83.4 \pm 12.4$ & $82.7 \pm 12.6$ & $81.2 \pm 8.4$ & $82.3 \pm 7.1^{*}$ \\
\hline FFM (kg) & $60.5 \pm 5.2$ & $59.8 \pm 5.3$ & $63.2 \pm 3.6$ & $64.3 \pm 3.2^{*}$ \\
\hline $\mathrm{FFM+BMC}(\mathrm{kg})$ & $63.6 \pm 5.3$ & $63.1 \pm 5.5$ & $66.4 \pm 3.4$ & $67.7 \pm 3.0^{*}$ \\
\hline $\mathrm{FM}(\mathrm{kg})$ & $19.7 \pm 7.0$ & $19.4 \pm 7.2$ & $14.7 \pm 4.9$ & $14.6 \pm 4.1$ \\
\hline$\%$ FAT & $23.1 \pm 4.4$ & $23.4 \pm 4.7$ & $18.1 \pm 3.6$ & $17.7 \pm 3.2^{*}$ \\
\hline
\end{tabular}

\begin{tabular}{|c|c|c|c|c|}
\hline \multicolumn{5}{|c|}{$\begin{array}{c}\text { Table } 3 \\
\text { The concentration of selected hormones and growth factors at rest before } \\
\text { and after the first } 6 \text { weeks of resistance training. All data are expressed as mean } \pm S D, * p<0.05\end{array}$} \\
\hline \multirow[t]{2}{*}{ Variable } & \multicolumn{2}{|c|}{ Group 1 - Hypoxia } & \multicolumn{2}{|c|}{ Group 2- Normoxia } \\
\hline & $\begin{array}{c}\text { Before } \\
\text { training }\end{array}$ & $\begin{array}{c}\text { After } \\
\text { training }\end{array}$ & $\begin{array}{c}\text { Before } \\
\text { training }\end{array}$ & $\begin{array}{c}\text { After } \\
\text { training }\end{array}$ \\
\hline IGF-1 (ng/ml) & $211 \pm 32$ & $293 \pm 40^{*}$ & $224 \pm 43$ & $235 \pm 36$ \\
\hline $\mathrm{GH}(\mathrm{ng} / \mathrm{ml})$ & $2.1 \pm 0.08$ & $1.8 \pm 0.2$ & $1.4 \pm 0.3$ & $0.6 \pm 0.04$ \\
\hline $\mathrm{T}$ (ng/dl) & $482 \pm 32$ & $486 \pm 20$ & $486 \pm 37$ & $497 \pm 49$ \\
\hline$C(\mu \mathrm{g} / \mathrm{dl})$ & $14.2 \pm 3.3$ & $13.9 \pm 3.1$ & $13.0 \pm 4.6$ & $13.1 \pm 2.8$ \\
\hline
\end{tabular}




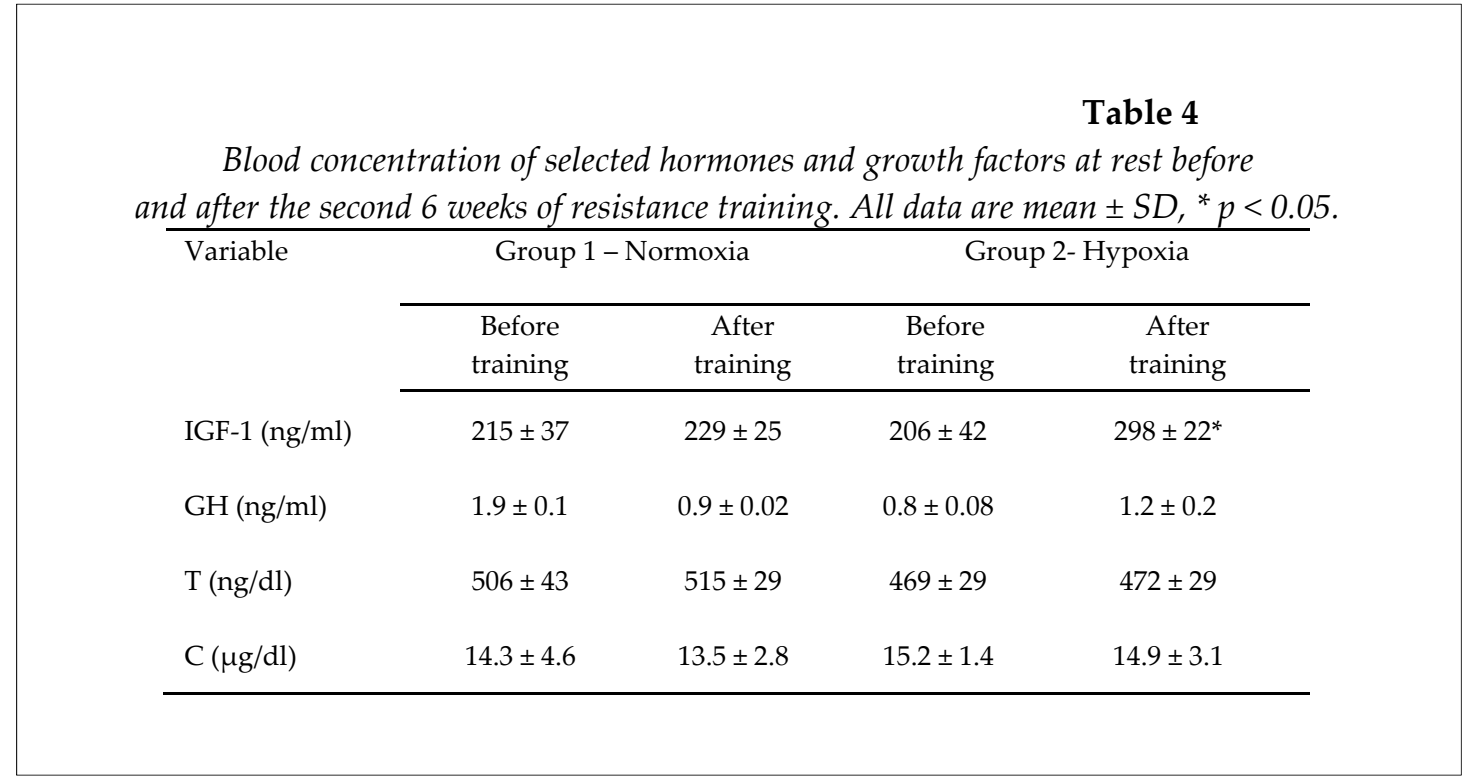

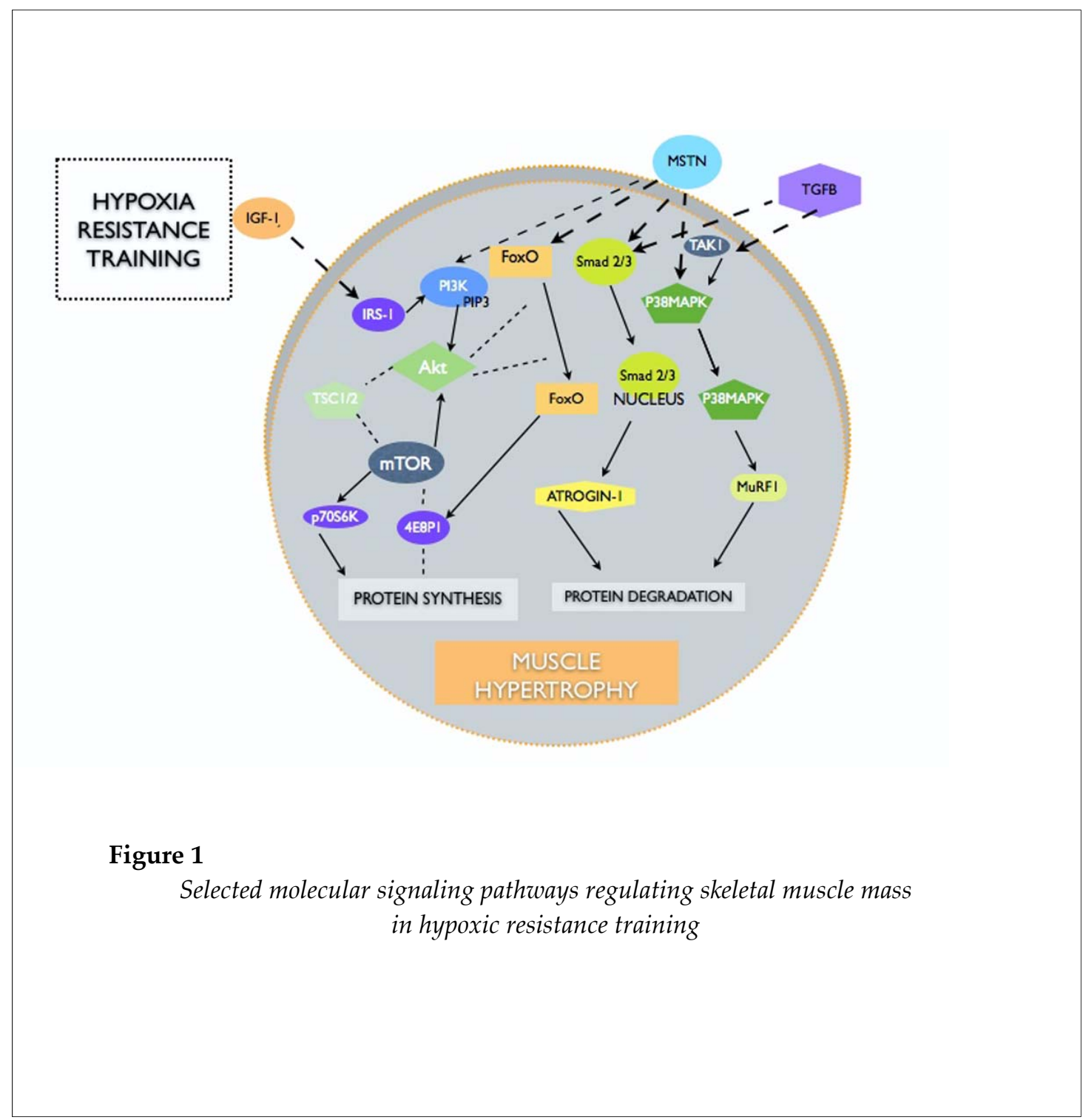




\section{Discussion}

Evidence exists that the adaptive response to resistance exercise is blunted in the hypoxic environment (Narici et al., 1995). However, the present study is the first to show that resistance training under normobaric hypoxia increases muscle mass as compared with normoxia.

Body mass and body composition changes, the so-called muscle hypertrophy phenomenon, are related to the activity of anabolic and catabolic signalling pathways which substantially depend on neuroendocrine factors. Maintaining muscle mass is a balance between protein synthesis and protein degradation. An increase in muscle mass can occur due to either an increase in protein synthesis or a decrease in degradation, while a decrease in muscle mass can take place as a result of decreasing protein synthesis or increasing protein degradation (Jonathan et al., 2013). The therapeutic importance of normobaric hypoxia and physical activity reflects structural, functional and molecular adaptive changes. It verifies the variation in concentration of biomarkers such as inflammatory factors, chemokines, hormones, as well gene expression.

Post training hormone secretion processes are particularly intensified as a result of muscle strength training with the use of maximum external loads and exercises involving large muscle groups (Kraemer, 2005), as in the case of our study. Hypoxia exposure and oxygen concentration in the range from 11.6 to $12.9 \%$ constitute a strong hormonal stimulus. Exercise is a potent physiological stimulus for GH, IGF-1 and testosterone secretion, and both aerobic and resistance exercise results in significant acute serum increases in hormone concentration and lactate. Anaerobic exercise performed in hypoxia could be a valid method to provide a greater stimulus to the anaerobic pathway equivalent to specific resistance training related to muscle property performance (Alveres-Herms et al., 2015). It was unclear, however, whether a combination of exercise and hypoxia therapy further would increase physical performance and changes in body composition, especially hypertrophy effects. Our research is the first to indicate a stronger neuroendocrine response of IGF-1 after resistance training performed in normobaric hypoxia (Gumucio, 2013). Combining resistance exercise and exposure to hypoxia has been shown to be superior to training under normoxic conditions in regard to the secretion of IGF-1. As a consequence, molecular signaling pathways were activated, regulating protein synthesis and the muscle hypertrophy effect (Chen et al., 2013).

Depending on the type of exercise, oxygen saturation (SpO2) duration and intensity of adaptive responses are different in nature (Casaburi et al., 2004). Decreases in SpO2 between 80 and $90 \%$ are experienced frequently, even at moderate altitudes $(4,300 \mathrm{~m}, \mathrm{FiO} 2=12 \% \mathrm{O} 2, \mathrm{SpO} 2$ $81 \pm 1 \%$ ) (Wolfel et al., 1991). It was reported that a short period of normobaric hypoxia $(\mathrm{FiO} 2=$ $12.9 \%, 4000 \mathrm{~m}$ ) was not sufficient to induce blunting in muscle protein synthesis, indicating that humans have a robust metabolic reserve against acute falls in SpO2 (Etheridge et al., 2011). This blockade seemed independent of the mTORC1 pathway since hypoxia did not modify the phosphorylation of S6K1 or the expression of REDD1, both at rest and after exercise (Etheridge et al., 2011).

In our study, repeated acute hypoxic exposure to hypoxia combined with resistance exercise increased the neuroendocrine secretion of IGF-1. In addition, our research suggests that acute resistance training under normobaric hypoxia $(\mathrm{FiO} 2=12.9 \%, 4000 \mathrm{~m})$ causes an increase in protein synthesis. These findings are consistent with the study on the combined effects of hypoxia and exercise which were also examined via an original experimental design, where a group of subjects climbed from 550 to $4559 \mathrm{~m}$ by foot, while another group was flown by a helicopter (Imoberdorf et al., 2006). The muscle protein synthesis rate was measured in both groups at sea level and at altitude. In the flight group, the rate of synthesis was not modified, whereas in the foot group, a $35 \%$ increase in protein synthesis was measured 19-23 hrs after the end of the exercise, suggesting that exercise was able to activate muscle protein synthesis even in hypoxia. On the other hand, it should be noted that an inhibition of muscle protein synthesis was also reported as a result of hypoxic resistance training (Mizuno et al., 2008; Liu et al., 2006).

One of the most widely studied activators of muscle hypertrophy includes IGF-1, which was elevated in the present study. Binding of IGF-1 to its receptor activates insulin receptor substrate-1, 
IRS-1, which then activates phosphatidylinositol3-kinase (PI3K), responsible for the conversion of intramembranous phosphoinositide- $(4,5)$ biphosphate (PIP2) to phosphoinositide-(3,4,5)triphosphate (PIP3). The IGF-1 receptor mediated activation of protein synthesis is PI3K dependent (Schiaffino, 2011). The serine/threonine kinase Akt (protein kinase B) binds PIP3 on the membrane through an N-terminal pleckstrin homology $(\mathrm{PH})$ domain and is activated by phosphoinositidedependent kinase-1 (PDK1). The recruitment of Akt to the membrane and the activation of Akt through PDK1 allow Akt to be released into cytosol to activate mTOR and other downstream effectors. In addition to IGF-1, there are also alternative spliced isoforms of IGF-1 that appear to have various roles in regulating skeletal muscle growth. mTOR has also been linked to intensification of protein synthesis due to resistance training under normobaric hypoxia (Jonathan et al., 2013). Exercise increases levels of growth factors in the muscle, including IGF-1, leads to the activation of the IGF-1 / PI3K / Akt /

\section{Acknowledgements}

The author's research is funded by a grant of the Ministry of Science and Higher Education of Poland (N RSA1 00 1451).

\section{References}

Alvarez-Herms J, Julia-Sanchez S, Corbi F, Pages T, Viscor G. Program of circuit resistance training under hupobaric hypoxia conditions improves the anaerobic performance of athletes. Science\&Sport, 2015; 2972: 10

Amann M, Eldridge MW, Lovering AT, Stickland MK, Pegelow DF, Dempsey JA. Arterial oxygenation influences central motor output and exercise performance via effects on peripheral locomotor muscle fatigue in humans. J Physiol, 2006; 575: 937-952

Bharadwaj H, Prasad J, Pramanik SN, Kishnani S, Zachariah T, Chaudhary KL, Sridharan K, Srivastava KK. Effect of prolonged exposure to high altitude on skeletal muscles of Indian soldiers. Def Sci J, 2000; 50: $167-176$

Czuba M, Maszczyk A, Gerasimuk D, Roczniok R, Fidos-Czuba O, Zając A, Gołaś A, Langfort J. The effects of hypobaric hypoxia on erythropoiesis, maximal oxygen uptake and energy cost of exercise in normoxia in elite biathletes. J Sports Sci Med, 2014; 13: 912-920

Czuba M, Waskiewicz Z, Zajac A, Poprzecki S, Cholewa J, Roczniok R. The effects of intermittent hypoxic training on aerobic capacity and endurance performance in cyclists. J Sports Sci Med, 2011; 10: 175-183

Czuba M, Zając A, Maszczyk A, Roczniok R, Poprzęcki S, Garbaciak W, Zając T. The effects of high intensity interval training in normobaric hypoxia on aerobic capacity in basketball players. J Hum Kinet, 2013; 39(4): 103-114

Brugarolas J, Lei K, Hurley RL, Manning BD, Reiling JH, Hafen E, Witters LA, Ellisen LW, Kaelin WG. Regulation of mTOR function in response to hypoxia by REDD1 and the TSC1/TSC2 tumor suppressor complex. Genes Dev, 2004; 18: 2893-2904

Casaburi R, Bhasin S, Cosentino L, Porszasz J, Somfay A, Lewis MI, Fournier M, Storer TW. Effects of 
testosterone and resistance training in men with chronic obstructive pulmonary disease. Am J Respir Crit Care Med, 2004; 170: 870-878

Chen SM, Lin HY, Kuo CH. Altitude training improves glycemic control. Chin J Physiol, 2013; 56, 193-198

Etheridge T, Atherton PJ, Wilkinson D, Selby A, Rankin D, Webborn N, Smith K, Watt PW. Effects of hypoxia on muscle protein synthesis and anabolic signaling at rest and in response to acute resistance exercise. Am J Physiol Endocrinol Metab, 2011; 301: 697-702

Friedmann B, Kinscherf R, Borisch S, Richter G, Bartsch P, Billeter R. Effects of low-resistance/highrepetition strength training in hypoxia on muscle structure and gene expression. Pflugers Arch, 2003; 446: 742-751

Ginnever H, Scanlon E, Roberts E, Murphy D, Lawley J, Chichester E. Body composition at high altitude: a randomized placebo-controlled trial of dietary carbohydrate supplementation. Am J Clin Nutr, 2009; 90: 1193-1202

Gumucio C, Mendias L. Atrogin-1, MuRF-1, and sarcopenia. Endocrine, 2013; 43(1): 12-21.

Hogan MC, Richardson RS, Haseler LJ. Human muscle performance and PCr hydrolysis with varied inspired oxygen fraction: a ${ }^{31}$ P-MRS study. J Appl Physiol, 1999; 86: 1367-1373

Imoberdorf R, Garlick PJ, McNurlan MA, Casella GA, Marini JC, Turgay M, Bartsch P, Ballmer PE. Skeletal muscle protein synthesis after active or passive ascent to high altitude. Med Sci Sports Exerc, 2006; 38: 1082-1087

Koumenis C, Wouters BG. "Translating" tumor hypoxia: unfolded protein response (UPR)-dependent and UPR-independent pathways. Mol Cancer Res, 2006; 4(16849518): 423-436

Kraemer WJ, Fleck SJ. Designing Resistance Training Program - Fourth Edition. Human Kinetics; 2014

Kraemer WJ, Ratamess NA. Hormonal Responses and Adaptations to Resistance Exercise and Training. Sports Med, 2005; 35(4): 339-361

Liu L, Cash TP, Jones RG, Keith B, Thompson CB, Simon MC. Hypoxia-induced energy stress regulates mRNA translation and cell growth. Mol Cell, 2006; 21: 521-531

Loenneke JP, Wilson JM, Marin PJ, Zourdos MC, Bemben MG. Low intensity blood flow restriction training: a meta-analysis. Eur J Appl Physiol, 2012; 112: 1849-1859

Macdonald JH, Oliver SJ, Hillyer K, Sanders S, Smith Z, Williams C, Yates D, Ginnever H, Scanlon E, Roberts E, Murphy D, Lawley J, Chichester E. Body composition at high altitude: a randomized placebo-controlled trial of dietary carbohydrate supplementation. Am J Clin Nutr, 2009; 90: 1193-1202

Mizuno M, Savard GK, Areskog N-H, Lundby C, Saltin B. Skeletal muscle adaptations to prolonged exposure to extreme altitude: a role of physical activity? High Alt Med Biol, 2008; 9: 311-317

Nishimura A, Sugita M, Kato K, Fukuda A, Sudo A, Uchida A. Hypoxia increases muscle hypertrophy induced by resistance training. Int J Sports Physiol Perform, 2010; 5: 497-508

Narici MV, Kayser B. Hypertrophic response of human skeletal muscle to strength training in hypoxia and normoxia. Eur J Appl Physiol Occup Physiol, 1995; 70: 213-219

Perrey S, Rupp T. Altitude-induced changes in muscle contractile properties. High Alt Med Biol., 2009; 10: $175-182$

Schiaffino S, Mammucari C. Regulation of skeletal muscle growth by the IGF1-Akt/PKB pathway: insights from genetic models. Skelet Muscle, 2011; 1(1): 4

Wolfel EE, Groves BM, Brooks GA, Butterfield GE, Mazzeo RS, Moore LG, Sutton JR, Bender PR, Dahms TE, McCullough RE. Oxygen transport during steady-state submaximal exercise in chronic hypoxia. J Appl Physiol, 1991; 70: 1129-1136

\section{Corresponding author:}

\section{Miłosz Czuba}

The Jerzy Kukuczka Academy of Physical Education in Katowice, Department of Sports Training, Poland E-mail : m.czuba@awf.katowice.pl 